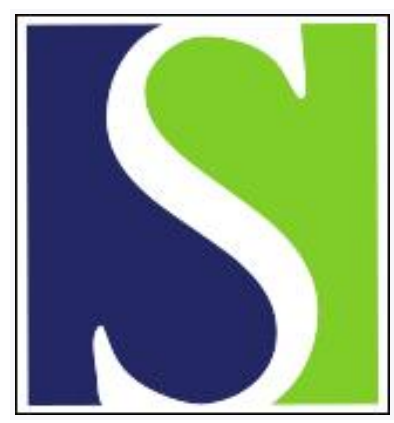

Scand J Work Environ Health 2006;32(6):515-527

https://doi.org/10.5271/sjweh.1056

Issue date: 31 Dec 2006

Job stress interventions and the organization of work

by Semmer NK

Affiliation: University of Bern, Department of Psychology, Muesmattstr 45, CH-3000 Bern 9, Switzerland.

Refers to the following text of the Journal: 2004;30(2):85-128

The following articles refer to this text: 2006;32(6):413-419; SJWEH

Supplements 2008;(4):25-29; SJWEH Supplements 2008;(5):14-21;

2008;34(3):169-178; 2009;35(1):7-18; 2016;42(3):192-200;

2018;44(1):58-68; 2019;45(6):529-532

Key terms: evaluation; health promotion; intervention; job design; job stress; organization-focused intervention; person-focused intervention; role clarification; task characteristics; work conditions; work organization

This article in PubMed: www.ncbi.nlm.nih.gov/pubmed/17173207 


\title{
Job stress interventions and the organization of work
}

\author{
by Norbert $K$ Semmer, $P h D^{1}$
}

\begin{abstract}
Semmer NK. Job stress interventions and the organization of work. Scand J Work Environ Health 2006;32(6, special issue):515-527.

Interventions that aim at improving health by changing the organization of work-in terms of task characteristics, work conditions, and social aspects-have shown their potential, but results are mixed, and many studies do not use their methodological potential. It is proposed that interventions at the organizational level are likely to have a more diverse effect than at the individual level, as the number of subsystems, with potentially diverging interests, is larger. Even well-implemented interventions are not likely to lead to improvements in all parameters for all participants, and trade-offs have to be considered. Methodological improvement is necessary but should not only focus on design issues, but also on careful documentation and subgroup analyses. A combination of person-focused and organization-focused approaches is the most promising. Finally, evidence points to the limited utility of economic arguments for the acceptance of health promotion projects; the necessity of professional trust is therefore emphasized.
\end{abstract}

Key terms evaluation; health promotion; job design; organization-focused intervention; person-focused intervention; role clarification; task characteristics; work characteristics, work conditions.

Ample evidence now shows that stress at work, especially when it is chronic, is a risk for psychological and physical health. This statement applies to a variety of stressors, such as high pressure, barriers to task accomplishment, or social conflict, as well as to a lack of resources, such as control, social support, or recognition, and other rewards. And it applies to a variety of outcomes, such as depression, psychosomatic complaints, back pain, and cardiovascular disease (1-5). Given this state of affairs, it seems "natural" that the promotion of health and the prevention of health problems should predominantly focus on creating a work environment that does not induce an undue amount of stress and that compensates for unavoidable stresses by characteristics such as high control and high rewards.

As is well known, however, reality differs. The main focus of prevention efforts is directed towards peopletheir stress management, their health behavior $(6,7)$. Many interventions that occur at work actually use this environment mainly as a setting in which people can easily be reached, rather than as an environment that might be changed - except for changing inducements to poor health behavior, for instance, by offering healthy food or taking away cigarette machines. [See the paper by O’Donnell (8).]
This state of affairs has been deplored by many authors, and, accordingly, many have asked for a stronger emphasis on changing the work organization. [See the paper by Kompier \& Cooper (9).] However, if one looks at published accounts of stress- and health-related interventions, the following quickly becomes apparent: (i) there is some evidence for the effectiveness of interventions that target person-health behavior and stress management (10-14) and (ii) there are not so many sound studies on the effectiveness of interventions that do change the work environment and the results of such studies are mixed and much less positive than those that refer to person-focused interventions $(6,7,10,13)$. [See, however, the paper by Taris (15).]

This contribution is not meant to be a comprehensive review of the literature. Rather, it focuses on issues that deserve attention from my perspective.

First, examples of projects are presented (grouped into three categories) that illustrate important issues. Several issues are then discussed in more detail in reference to (i) levels of intervention, such as organizational and individual levels, (ii) inconsistencies in outcomes, (iii) compensatory and side effects, (iv) methodological aspects, and, finally, (v) the focus of change. The paper ends with a summary of conclusions and

1 University of Bern, Bern, Switzerland.

Reprint requests to: Norbert K Semmer, University of Bern, Department of Psychology, Muesmattstr 45, CH-3000 Bern 9, Switzerland. [E-mail: ] 
some final thoughts. The paper especially focuses on what can reasonably be expected from projects that try to foster health by changing the organization of work and what should be done in order to better understand the mechanisms involved and to increase the chances for better outcomes.

\section{Domains of intervention and typical findings}

One can usefully group efforts aimed at changing the organization of work into the following three categories: (i) task characteristics, (ii) work conditions, and (iii) social conditions (6). Of course, the boundaries between such approaches are often not very clearcut, and many projects combine several elements. In the following section, each approach is described briefly and illustrated with examples. These examples are intended to highlight important issues that are then discussed.

\section{Task characteristics}

There is widespread agreement that the very tasks that people have to fulfill are important for health and wellbeing, repetitive and boring tasks being negative and sufficiently-but not overly_complex tasks being positive (16-18).

Although many of the concepts regarding "good" or "human" job design were not developed with a particular emphasis on health, but rather with regard to more general-often motivational-considerations (16, 19$21)$, some intervention studies in that tradition have measured health outcomes.

As an example, one of the best-known studies in this area concerns an intervention in a department of a confectionery company (22). It was prompted by problems such as low morale, poor relations between management and the shop floor, and concomitant problems such as high turnover. Changes concentrated on two aspects of the job characteristics model (21). Task identity was increased by removing barriers in the production hall to make the whole process visible, and autonomy was given to the group who now could decide on the allocation of tasks, on rest breaks, on production speed, and the like. Measures were taken 5 months after the project started but before changes took effect, and then again 18 and 28 months later. Changes were observed in the aspects of the model that were targeted (perceived identity, autonomy), but not in skill variety and significance, making a Hawthorne effect unlikely.

There were improvements in intrinsic motivation, job satisfaction, performance, and mental health (General Health Questionnaire). These latter effects were observed for all three intervals (time 1-time 2, time 2time 3, and time 1-time 3), but the long-term effects were strongest. Despite the lack of a control group, the study convincingly demonstrated that the effects were specific to the attempted changes and thus lent credibility to attributing the effects on well-being to the increase in autonomy and identity.

Incidentally, this study shows that even with a rather weak design - there was no control group — it is possible to incorporate features that make alternative explanations more unlikely. This is a topic that will be taken up later, as many studies have not used their potential to the full and could well go further, even with a weak design.

However, a later study that had a similar approach failed to replicate the findings with regard to mental health (23). The results were favorable for job satisfaction, especially for intrinsic job satisfaction, and for productivity, in that the same level of performance was achieved with less personnel (ie, without a supervisor). Intrinsic motivation, organizational commitment, or mental health did not improve, however. The last-mentioned even declined for one experimental group, although this group's score still compared favorably with that of the general population. Turnover actually increased. The authors attributed this finding to pressure for production and to a reluctance of team members to react to disciplinary problems. As a result of the latter, such problems were dealt with only at later stages, when problems had already become intense.

These two studies contain several messages. First, it is possible to achieve positive health-related outcomes by changing the nature of tasks. Second, the results of different studies are not necessarily consistent. Of the measures that refer to health and well-being, job satisfaction improved in both studies, but mental health improved in only one of them. And turnover actually increased.

Of course, this is only an example. But even a quick look into the literature shows that inconsistencies are more the rule than the exception. Inconsistent results, therefore, are an important point that deserves to be discussed. This point will be taken up later.

A study by Smith \& Zehel (24) illustrates another point. It concerned wrappers, meat processors, and cutters in a meat processing company. Its original focus on upper-extremity cumulative trauma disorders was broadened to more general aspects of stressful work conditions, such as machine pacing, short cycles, harsh physical environment, and the potential for job loss. "Focus groups" recommended job rotation, which was introduced.

After 1 year, the wrappers showed reduced musculoskeletal problems and psychosomatic complaints and improved appraisal of work conditions (eg, concerning 
pressure to work fast). Meat processors showed a mixed picture. The cutters profited somewhat in terms of musculoskeletal complaints, psychosomatic symptoms, and pressure to work hard, but reported less job control and lower job satisfaction.

Interestingly, it was those who had the worst conditions at the outset, the wrappers, who profited the most clearly. The cutters, on the other hand, who originally had the most skilled and prestigious jobs, evidently resented the skill devaluation resulting from rotating to the other tasks and therefore deteriorated in job satisfaction, although they improved with respect to strain.

The study illustrates (i) that results may differ for different groups and (ii) that some symptoms ("classic stress symptoms"- -see the section on inconsistencies in outcome variables) may improve, while other indicators of well-being (ie, attitudinal variables such as job satisfaction) deteriorate. Again, these are issues are discussed later.

The study also presents an example of an investigation that does not use its full potential. Although quantitative data were gathered, they were not properly analyzed, and the report confines itself to a narrative description. Note that this criticism does not simply say "They do not have the optimal design". Rather, the emphasis is on the fact that the authors were not using their potential, even within the limits of their design.

\section{Work conditions}

The second category of interventions refers to work conditions, such as ergonomic issues (eg, office furniture, drivers' seats, noise reduction, usability of computer programs), worktime, or workload.

As an example, Evans et al $(25,26)$ reported a study on improving work conditions for Stockholm bus drivers. Changes included (i) improved street maintenance, broadening of road segments, (ii) route reconfigurations, (iii) improvements in separate bus lines, (iv) more even spacing of and (v) better access to bus stops, (vi) traffic signal priority for buses, and (vii) an automatic passenger information system.

A three-phase survey showed a reduction in perceived workload after 1.5 years, whereas perceived workload changes in a control group were not significant. No other differences were significant-and that includes, most notably, health-related parameters.

In addition, a field study was concerned with concrete driving experiences. It included questionnaires, observation data by investigators riding on the bus, and physiological measurements. This study yielded a significant decrease in observer-reported hassles, heart rate at work, and distress after work in the intervention group $(\mathrm{N}=10)$ but not in the control group $(\mathrm{N}=31)$. Furthermore, physiological changes and perceived stress cor- related with driver experimental status (intervention or control). These latter correlations became nonsignificant when the hassles change score was controlled for. Thus the intervention had a positive impact on immediate reactions throughout the workday, but not with regard to long-term changes. The problem of long-term and shortterm changes constitutes another issue that will be taken up later.

A final example refers to a project in which worktime was reduced for bus drivers (27, case 1$)$. The intervention led to a reduction in back pain (significant in comparison with that of the control group) and several other changes, not all of which were, however, significantly different from those of the control group. (Significance was, however, not easy to achieve, as the control group contained only 26 persons). This was a study with a rather strong design, having a control group. In addition, a variety of measures was used. As there was also a workshop on health promotion, there was possible confounding with a person-focused intervention. But altogether this study constitutes a rather good example, with encouraging results.

\section{Role clarification and social relationships}

The final category refers to social relations. As such aspects as poor social relationships, conflicts with others, or lack of social support constitute one of the most important stress factors (28), improving social relationships should be a promising avenue. This procedure constitutes an interesting mix of approaches that are both person-focused and structurally oriented. The training itself is person-oriented. One tries to improve people's social behavior in terms of better leadership, better social support, and the like. At the same time, the social behavior of those who are trained, such as supervisors, constitutes part of the work environment for others. Interestingly, not too many studies have tried this approach.

Heaney et al (29) trained people who worked in homes for the mentally ill in the recognition and mobilization of social support, as well as in problem solving. The participants were expected to train their peers. After 3 months, significant improvements were found concerning (i) supportive feedback by supervisors, (ii) self-appraisal of coping, and (iii) team climate. Marginally significant effects emerged for work-team functioning and one health-related parameter, that is, somatic symptoms. No effects were found for supervisor support in general and another health-related parameter, that is, depressive symptoms. Given that there were more than 1200 participants, marginally significant changes were not likely to indicate substantial changes. On the other hand, people who did not show up were counted as belonging to the experimental group, and, therefore, the whole evaluation can be considered 
conservative. And, indeed, the changes in the health parameters were significant for those who did participate.

Furthermore, and it is one reason why this study is being mentioned, the authors performed a very interesting additional analysis. They determined the profile of people that had dropped out-either because they left the program or because they left their job altogether. And they determined the similarity to this profile for people that remained in the program by way of a probit analysis. This approach enabled them to estimate the probability of dropping out for people that actually did remain in the program. The results showed an interaction between this probability and the treatment, which implies that the effects were especially strong for the participants whose characteristics implied a high risk of dropping out. This is a very important result, and an especially intriguing way of analyzing the data. Thus, this study is especially interesting because (i) it had a strong design, that is, a control group, with random allocation, and (ii) it used sophisticated analyses that showed that, although the overall effect was not very strong, there were effects for those who participated, and, among them, especially for those at high risk of dropping out ${ }^{2}$. This type of analysis should become much more common, as it offers information about variables that are responsible for success or failure.

The goal of this article is not to give a representative overview of studies. This brief review will therefore end here with a short summary of typical findings ${ }^{3}$. Subsequently, several issues are discussed in reference to the levels of intervention, inconsistencies in the outcome variables, compensatory and side effects, and methodology.

\section{Summary of typical findings}

It is not easy to summarize the findings from the different studies. With regard to methodology, one finds a large variety in the quality of designs - unfortunately, with a preponderance of weak designs. Interestingly, the designs tend to be stronger for the social relations studies and for the more ergonomically oriented studies, less so for changes in the design of tasks themselves.

Furthermore, many studies with rather weak designs-for instance, designs without a control groupdid not even go to the limits within the designs they used. This problem has already been mentioned, and is taken up a little later.
What is striking is certainly that the results are inconsistent. The effects vary greatly, and different measures do not often converge. Typically, there are more short-term than long-term effects. There are also more effects for variables that are directly targeted [eg, workload in the Stockholm bus driver study $(25,26)$; role ambiguity in a study by Schaubroeck et al (30)] than for the effects that were intended to result from a change in these targeted variables, that is, an effect on health indicators.

On the positive side, there are some indications for dose-response relationships [eg, the amount of role clarification achieved correlated with psychological health in the study by Schaubroeck et al (30)].

If one tries to identify outcome variables for which effects are more consistently found than for others, it seems that the most consistent effects emerged with regard to two variables, job satisfaction and absenteeism.

Overall, it is fair to say that there have been many positive effects and many null effects, but few negative effects. This outcome is important, and it is good news, because it means that, although a program might have no effect, at least it is not likely to damage people!

Looking at variables for which a negative effect does occur with some regularity, one finds, for the most part, an increase in time pressure and workload.

In summary, despite all of the problems, a cautiously positive conclusion is warranted. Work-related interventions have shown that they have the potential to improve health and well-being.

This finding, of course, implies that one cannot tell employers that we know a certain intervention is going to work. It is very difficult to be sure in advance-much less, in fact, than for person-oriented interventions! This situation should be stated very clearly.

In my view, there are some theoretical, practical, and methodological reasons for this state of affairs, and they have implications for what further research we might focus on more strongly.

\section{Issues to consider}

In the following, some issues are discussed that characterize projects in this area, as well as issues that, in my view, deserve more attention. Specifically, the issues of levels of intervention, inconsistencies in outcome variables, compensatory and side effects, and methodology are dealt with. not mention these important refinements and, by averaging the effects, report this study as having negligible effects. For more detailed discussions of these issues, see the papers by Semmer (6) and Schaubroeck et al (30). 


\section{The issue of levels: organizational and individual interventions}

In a recent review on work organization interventions, Murphy \& Sauter (7) raised the issue of levels-distinguishing between the levels of (i) legislation and policy (eg, concerning workhours, worker compensation, social security), (ii) employer or organization (eg, workfamily programs, return-to-work programs), (iii) job or task (eg, task redesign, provision of light-duty jobs), and (iv) individual (eg, health promotion, stress management, employment assistance programs). Murphy \& Sauter deplored the lack of research at level 1, which has not been treated in this paper, as it focuses on organizational issues. In commenting on Murphy \& Sauter's article, I have earlier (31) argued that the effects of an intervention will be less predictable as the level increases, because one is dealing with increasingly complex social systems. This conclusion implies that more and more subsystems will be involved, whose interests may diverge, who are differentially enthusiastic about the change, and the like, so that some subsystems may support the change, whereas others may be indifferent or even undermine it.

Examining this argument for changes in the organization of work, which are the focus of this paper, leads to a focus on divergences between various subsystems. Thus, when one tries to redesign work, each person who participates faces individual challenges, such as coping with change, which many studies have shown to be stressful (32). Some people may react in a defensive way, for instance, because they are afraid of losing privileges, or afraid of change per se, because they do not possess enough self-efficacy. This situation implies that each person has to cope with his or her own problems, as well as with the reactions of other group members. Often, compromises may have to be found that are less than satisfying for some. Furthermore, the environment reacts to the group. Other groups may envy a "pilot" group, outside specialists might fear losing influence, management may promise support but not stick to it, and the like.

Developments may also occur that compensate for increased resources by increasing demands as well. These developments may be based on changing circumstances or management decisions. Indeed, some reports concern, for instance, autonomous working groups who complain that the pressure they experience has increased (33). [See also the paper by Semmer (6).]

Finally, the system may also experience changes other than the "planned change". These changes may be unrelated to the project but have an impact on them. As an example, everyone agrees that management support is crucial for a project (see below). This support is often tied to specific persons who give enthusiastic support. If, for whatever reason, such a person leaves, the situation may become very difficult. Single events such as this one can well be decisive as regards the success or failure of a project.

By contrast, a stress management program at the individual level can target the very aspects that bother a particular person. One can learn to (i) reinterpret some events in a more benign way (eg, ask if seemingly hostile behavior of other people may, in fact, be due to a lack of competence rather than hostile intentions), (ii) cope more efficiently with some potentially stressful circumstances (eg, by more-efficient planning, by being more assertive), or (iii) take action in order to change aspects of the environment that one has analyzed as stressful and changeable-for instance, by suggesting changes in the work organization, in ergonomic issues, or in measures that make it easier to combine work and family obligations (34). This last point especially deserves to be emphasized. A stress management program does not have to confine itself to dealing with symptoms only (eg, by relaxation). It may also include aspects of problem analysis and problem solving, as, for instance, envisaged in many cognitive-behavioral programs such as stress inoculation training (35), or can be focused centrally, for example, in programs like Bunce \& West's innovation training (36). Finally, such competences may well be useful for dealing with stress outside work - and it must be kept in mind that work is an important factor for health, but certainly not the only one. The variance explained by work can be estimated to be around $15 \%$ (37).

All this implies that, with personal stress management programs, one is working exactly at the interface of the individual and his or her (work) life, where the problems present themselves. If the program is well done, a good chance for success seems plausible, as people can deal precisely with their "idiosyncratic problems" (7).

Such factors actually favor the probability of success for individual interventions. These considerations, as well as the well-documented success of individual stress management, argue against pitting the two approaches against each other, and also for an approach that tries to integrate them (see below).

For attempts to improve health by changing the organization of work, the presented arguments imply that this is an undertaking that contains some inherent risks of failure-even if well done. The consequences of intervening in complex social systems are never fully predictable and, therefore, imply that, in the end, one might have to settle for a criterion for success that is well below $100 \%$. Such modest aspirations should also be considered against the background of many failures of projects at restructuring organizations in general, that is, without specific reference to health problems. Such 
failures occur frequently even for efforts that are purportedly driven exclusively by economic concerns, such as mergers and acquisitions, which are estimated to fail at rates between $50 \%$ and $80 \%$ (38). One implication of this reasoning is that change agents and health professionals should resist the pressure to make overly optimistic promises about change projects, be realistic in the prognoses they make and inform employers, as well as participants, about both risks and chances [analogous to Wanous' realistic job preview (39)].

This conclusion should not, however, serve as an excuse for failing projects. It is still mandatory to analyze the reasons for success and failure very thoroughly so that the chances of further success can be maximized.

\section{Inconsistencies in outcome variables}

Many projects do find improvement in some parameters, but it is very difficult to predict which outcome variables will improve. Sometimes there will be improvement in job satisfaction but not in somatic symptoms, and sometimes vice versa. Sometimes there will be improvements in back pain, sometimes in cardiovascular parameters-but not so often in both. And so forth.

Partly, such results may be due to small samples. And the issue of sampling error should not be underestimated. Although we may be trained in statistics, we often tend to look for substantive explanations in our results, ignoring simple chance. Maxwell (40) illustrates very convincingly the small probability that all effects that are actually present in a population will be detected in samples, unless they are really large. Meta-analysis is a good way of dealing with this issue, but it presupposes that a large enough number of good studies is available to produce a good meta-analysis.

Partly, this diversity of outcomes may also be due to people being in different stages. Among people who take part in interventions, there may be people who are stressed but have not developed symptoms, there may be people who are stressed and have already developed symptoms, but there may also be people who are not stressed very much. [See the paper by Kompier \& Kristensen (41).] And for the group that is not highly stressed (which, incidentally, is the only group for which the intervention is really a primary one), one has to reckon with a floor effect. For them, the level of symptoms is very low, and so there is not much room, or necessity, for improvement. The participants who are stressed and have some symptoms, but are in a stage in which the symptoms have not become chronic, may be those who profit most. Among those, however, who have developed chronic symptoms, the symptoms may have acquired some autonomous qualities, that is, they may persist even after stress factors are removed [according to what Frese \& Zapf (42), call an "accumula- tion model"]. An example would be people who have experienced a major, and stressful, setback, which they worry about a lot. After things have gone back to normal, they may continue worrying even in times when there is no obvious threat. They may even get worse because of some inner dynamics, for instance, because of a general weakening of resources, as would be exemplified by a greater susceptibility to all kinds of infections because of a weakened immune system ["dynamic accumulation model" according to Frese \& Zapf (42)]. Such mechanisms may help explain why one often finds effects for variables that have been targeted (eg, autonomy, social support) but no effects on health variables that are supposed to be influenced by the parameters that were targeted. If symptoms have already become chronic, the change in work characteristics may be noticed-and appreciated-but will not necessarily result in noticeably better health and well-being. The findings about the relatively poor health of former shift workers are a case in point (43). Such symptoms may require more intensive personal treatment-which is another argument for a combination of structural and personal interventions. This potential diversity of participants often is not taken into account in the analysis of effects.

Looking at outcome variables in terms of content, it may-although cautiously — be concluded that there are two variables that show the most consistent results, job satisfaction and absenteeism (6). Note that job satisfaction is an indicator of mental health mainly in terms of an attitude, as it is based primarily on an evaluation of one's situation. It seems that such attitudinal variables are easier to change than "classic" stress symptoms, as reflected, for instance, in "psychosomatic" measures such as the General Health Questionnaire. This difference may stem from attitudes varying mainly along the "evaluation" dimension of the emotional circumflex and not implying high arousal (17), whereas the "classic" symptoms involve high arousal in addition to a negative evaluation. This high negative arousal may lead to increased reactivity and a general dysregulation of physiological systems (44), and eventually to the development of irreversible damage [eg, with regard to cardiovascular problems or impaired immune functions (45)]. Absenteeism is conceptually a very promising variable because it is influenced both by people's health and by their attitudes towards the job and the employer, the attitudinal aspects being more important for the frequency of short-term absences (46). Thus any changes towards the positive may combine to reduce absenteeism.

There are indications that attitudinal measures have a stronger relationship to job content and resources (eg, control), whereas classic symptoms of strain-mostly negative indicators-have a stronger relationship to classic stressors $(17,47)$. 
Such considerations may explain some of the results of Smith \& Zehel (24). The cutters, who were the most privileged ones, showed improvement in musculoskeletal complaints because some of their demands were reduced. At the same time, however, they showed a deterioration in job satisfaction, probably because the job rotation forced them to execute some tasks that they considered to be of lower status.

To the extent that such processes are operating, the picture with regard to divergent outcomes may become even more complicated because these processes may lead to "paradoxical" effects of stress. Some variablessuch as high demands - may be stressful and be associated with a higher risk of stress symptoms. At the same time, however, dealing with high demands may well enhance feelings of accomplishment, self-esteem, and job satisfaction (48). This aspect has not yet received due attention in the literature. It may well represent one reason why "letting go" is so difficult for people in highly qualified jobs. Reducing one's load might reduce stress through overload, but it also may reduce feelings of accomplishment and pride.

On a more general level, all this discussion leads to the conclusion that it may not be reasonable to expect positive changes in all indicators of health or well-being. Some variables may change, some may not, and some may change in some people but not in others. This situation implies, again, that one should not have expectations that are too high. It also implies that data should be carefully analyzed with regard to subgroups for which changes do, or do not, occur.

The study by Heaney et al (29) is a good example, showing that the project yielded improvements that were especially strong for those who had a high risk of dropping out. Randall et al (49) have also recently shown that a program may not be successful overall but still be successful for those who participate, and they argue for "adapted study" designs that shed light on such differences.

Getting to know more about who participates, who does not, and who starts but drops out is an obvious implication of these considerations. One might speculate that those who did not participate may be those that needed it most. Fortunately, however, there are indications that those who attend do so because there is a need (50).

Within this framework of looking for specific rather than overall effects, one also might consider what might be called the "individualization" of outcome variables. For instance, it is conceivable that people have individual symptoms of stress, with some reacting with stomach pain, others with back pain. If, as a result of work reorganization, changes in these specific symptoms occur, the changes would indicate a very good result. As the effect is only on specific items, however, it might not show in the scale mean, as, for most items, there will be no change. If one could determine in advance which are the most typical stress symptoms for a given person, analyses might be tailored accordingly and thus yield measures that are much more sensitive than the more global ones (51).

In summary, differentiating between outcomes in terms of attitudes or evaluations on one hand and "classic" strain symptoms on the other, differentiating between different groups of participants and nonparticipants, and tailoring outcome measures to the sensitive points of individuals might increase understanding, and it might well indicate more success for some projects than are shown by global overall measures.

\section{Compensatory and side effects}

In changing the focus from outcome variables to work characteristics, it seems necessary to consider consequences that are not intended. One such consequence refers to "compensatory effects". Changes do not occur in a vacuum. Work continues, plans are being made, goals are being set, orders come in, and so forth. And sometimes positive developments may induce compensatory decisions.

Thus, when a group that has been given more autonomy is functioning well, supervisors might think that the group could do more. And, indeed, members of socalled autonomous work groups often report that their workload has increased (33). But even without a deliberate decision by anybody, many positive developments may have side effects. Thus Wall et al (23) have reported higher turnover in autonomous work groups. They attributed this turnover to the fact that the groups had to deal with the dysfunctional behavior of some of their members. This job had previously been the responsibility of their supervisor. When there was no longer any supervisor, the group had to make decisions that were hard and involved potential conflict. The groups evidently avoided such decisions until the problem became so manifest that it could no longer be solved by normal means of conflict resolution, the result being higher turnover.

This example illustrates how good things may come at a price_not only may people make more decisions, but they must also make certain decisions that they might prefer not to make (52). Again, this situation points to the necessity of combining structural and personal approaches-as people must be prepared and trained to make such decisions and to cope with the conflicts that may be associated with them.

Furthermore, as already outlined, many work arrangements that we might not consider optimal may well be advantageous to some. Actually, one implication from systems theory (53) is that, whenever one encounters something that looks dysfunctional for the system 
as a whole, it is likely that there are some people or groups (subsystems) who profit from this state of affairs. Thus a strict division of labor, with tasks divided between specialists on one hand and operators with little skill and autonomy on the other, may not be very functional for the system as a whole, and for the group of operators. The specialists, on the other hand, may profit from this in terms of enjoying privileges and maintaining high self-esteem. Giving more autonomy to others (the operators), and increasing these people's skills, may threaten privileged positions and thus induce resistance. Sometimes this outcome can be compensated for [eg, by promoting the specialist, by finding a new role for supervisors whose power is reduced by empowering their subordinates (eg, managing boundary relations)], but this might not always be the case.

The conclusion from this discussion is that we may have to think more in terms of trade-offs than we may be used to. We tend to think of a "good work environment". We may have to think about improvements for some, but problems for others, and some side effects even for those who profit. Therefore, rather than talking about a "good" outcome, one might have to settle for outcomes in which the positive effects are stronger, or more important, than the negative ones.

To avoid misunderstandings, I must add that this conclusion does not to support an attitude of "anything goes". It is absolutely essential to look carefully at what is possible and what is not, and at whether the advantages are worth it in light of the possible disadvantages. Therefore, analyses must be more careful rather than less careful.

\section{Methodological aspects}

Design aspects. As is often deplored, not many studies have used really strong designs, that is, as least quasiexperimental designs, which include a control group. We all know that such designs are preferable, but we also know that they are often not easy to implement, to say the least. [See the paper by Kompier \& Kristensen (41).]

Nevertheless, it is interesting to see that it is possible to develop what might be called a "culture of evaluation". This culture manifests itself in a number of projects in the area of health promotion, such as employee assistance programs that have been evaluated in a rather sophisticated way, some even with companies as the unit of analysis (13). [For a review, see the paper by Terborg (54).]

Therefore, although it may well be advisable that academics should sometimes show more appreciation for the constraints faced by practitioners, more does seem possible. However, the methodological discussion sometimes focuses too much on issues of design.
Experimental and quasi-experimental designs have been developed to make alternative explanations unlikely. But there are other possibilities that may decrease the likelihood for alternative explanations as well.

Thus Wall \& Clegg (22) had no control group. But they could show that the effects on work conditions were specific to the changes induced, and this finding supports the argument that the changes in the outcome variables were due to the changes in work characteristics induced by the project. Other examples are analyses like those of Randall et al (49), who separated participants from nonparticipants, or those of Heaney et al (29), who identified people at risk by their similarity to people who actually dropped out and used this similarity as a predictor.

All this requires sound methodological thinkingbut not reduced to "Do I have the correct design?" Often, the more important question is: "What kind of information do I have-or could I gather-to render alternative explanations for my effects implausible or to explain the effects obtained?"

Process aspects. The overemphasis on issues of design has also led to a neglect of process considerations in evaluation. There is little doubt that many interventions fail because of implementation problems.

Thus, everybody seems to agree that support by management is crucial $(7,55,56)$. And many authors report that it was not given strongly, or consistently, enough. There is also widespread agreement that a participative approach is the most promising — both for substantive reasons, as the people who work at the place often know both the problems and the best solutions, and for motivational reasons, as people identify more with a project if they perceive themselves to be agents of change rather than objects of change $(56,57)$.

Furthermore, almost everyone would agree that the skills of change agents who manage a project are crucial (58). Will they be able to motivate people? Will they be able to ensure that group discussions will come to concrete solutions? Will they be able to help groups develop realistic expectations and avoid the two extremes of (i) an over-enthusiastic attitude, which leads to overly optimistic expectations that most certainly will not be fulfilled, and (ii) a resignative attitude, which may develop after (inevitable) setbacks, leading to a loss of motivation and to withdrawal. Will they manage the project without "taking over", without becoming "powerful experts" who manage the whole project-which implies that people do not feel that they are the real "agents of change" and thus may reduce their commitment, but also blame the change agents when things do not develop as anticipated? Will they refrain from forming coalitions with some people in the company, who might use this coalition for other purposes (organizational 
politics)? Are they able demonstrate expertise without acting in an arrogant and offending way? Are they able to admit errors without becoming defensive?

The list could be complemented by many other aspects-many of them can be found, for instance, in the work by Kompier and his co-authors $(27,56,59,60)$, who should be lauded for emphasizing "obstructing" as well as "stimulating" factors. Schaubroeck et al (31) have also provided a good example for both the feasibility and the importance of relatively simple process measures. Although the effects of their role clarification interventions were weak in general, they could show that the amount of role clarification actually implemented by the supervisors was related to the psychological health of their subordinates.

The problem is that many of these factors are often not reported at all, such as the qualification, the skills, and the behavior of change agents. Or they are reported in a more or less anecdotal way. Therefore, for instance, it remains unclear how many projects failed because they were not implemented skillfully, because key people left, or the like. All of these factors imply that, in many cases, crucial information has not been available for a systematic evaluation. Process evaluation should, therefore, be more prominent in our research $(49,55)$. This need is even more important when it is considered that many interventions do not seem to be carried out as intended (61).

But it must be emphasized that this type of evaluation is more than a narrative account of things. It requires the careful documentation of as much information as possible in a systematic fashion. This careful documentation might imply, for instance, (i) data on how many people attended which meeting, how often managers were present, how quickly management reacted to questions and proposals and how often to the positive or negative; (ii) participants' ratings of their satisfaction with meetings after each session, as well as their judgment of the behavior of change agents, their level of trust, and the like, using very short scales; (iii) documentations of meetings by external observers (eg, students), referring to what happened, but also rating aspects like atmosphere, concreteness of the discussion, skillfulness of the behavior of change agents, and the like; and (iv) documentation of external events, such as changes in personnel or management, conflicts, and the like.

Data of this kind could be very valuable, indeed. Imagine, for instance, a project that failed. If the authors could document that satisfaction with meetings was high over a given period and started to drop after a given event, such as a supportive manager leaving, or a longdebated suggestion being turned down, or if they could document how enthusiasm and trust were initially high but slowly eroded, and that this erosion corresponded to diminishing attendance at meetings by crucial people, things could be analyzed in the logic of time series. Such analyses could take the interpretations by authors out of the realm of anecdotes and support them with data.

The conclusion from these considerations is simple: Go as far as possible in terms of design. But regardless of your design, carefully note and document events and processes so that this information can be tied to outcome variables.

\section{The focus of change: comprehensive approaches}

Work versus person? Although changing the environment is often seen as a "natural primacy", it has become increasingly clear that structural and personal changes should not be pitted against one another (6). There are several reasons for this argument. First, change per se is often stressful; efforts to restructure work imply that new demands must be met (see the section on dealing with conflict), and even projects that are well designed and implemented run the risk of setbacks. This situation implies that, in order to deal with these problems, people need personal (or internal) resources (such as energy, self-efficacy, optimism, problem-solving skills, conflict resolution skills). Second, even in well-designed work environments, a certain number of stressors will be unavoidable (eg, dealing with suffering and death in medical and social settings, dealing with unfriendly clients in service occupations, dealing with emergencies, dealing with short deadlines, and the like). This situation, again, implies that personal resources for dealing with stress are necessary. Third, to the extent that symptoms have become chronic, they will not necessarily change when the conditions that produced them are changed; rather, personalized intervention will be needed. Fourth, some stressors are, at least partly, selfcreated; thus, people low in emotional stability or agreeableness, or low in social competences, may antagonize others and create, or "fuel", social stressors (62). Fifth, one of the mechanisms through which chronic stress affects people is the impairment of their personal resources $(44,63)$. Thus symptoms like fatigue, sleeplessness, lack of self-efficacy, and the like are often indicators of reduced capabilities (resources) to deal with problems. This situation implies that there is a chance that the very people that would need structural changes most may have the least resources to deal with the stress associated with them, and to make use of the new options that are being created. And finally, in many cases, the very aspects of work that create stress (eg, meeting deadlines) can also be a source of pride and well-being if and when the demands are mastered (64). While it is necessary in such cases to limit the load to manageable amounts (structural intervention), the goal cannot be to eliminate the load altogether, but rather to strengthen personal resources for dealing with it and thus to make 
experiences of success possible. This effort may require an adaptation of the work environment to specific personal strengths and weaknesses.

These problems are exemplified by evidence related to the stress-buffering effect of control, as postulated by the job-demands-control model (65). This stressbuffering effect is found only for people who have the internal (or personal) resources to use control (a structural resource) effectively. These internal resources are reflected, for instance, in high self-efficacy or internal locus of control (66). Unless personal resources are built up together with structural ones, the structural options may not be used (or may even be damaging) because the resources to put them to use are lacking.

In line with this argument, Larsson et al (34) have reported a project in which health circles in schools discussed experienced stress and ways cope with it, as well as ways to alter it, combined with relaxation training. This approach resulted in several improvements, as compared with the situation in a control group, which included stress reactions but also attempts to change stressors in their environment. This finding indicates that "the programme may have contributed to a release of inner resources which were directed towards the external world" (34).

Comprehensive approaches: work and person. Fortunately, the discussion about changing work versus the person seems to be waning, giving way to an emphasis on more comprehensive and integrative approaches (56, 67, 68). An important element of many such interventions is a participatory approach, which implies control and empowerment for those involved (69). In addition, it increases the chances that exactly those problems are being focused on that are important for those involved, regardless of whether they are structural or personal. A participatory approach is likely to ensure a good risk assessment (rather than offering a program "off the shelf"), and a profound risk assessment is an important prerequisite for a focused intervention $(56,61)$. Furthermore, participation is likely to enhance the chances that changes will be accepted as meaningful and integrated into the organizational culture, rather than being perceived cynically (70), and perhaps supported only superficially or even undermined. [Note that the most consistent predictor of satisfaction with work-family balance in a large study by Saltzstein et al (71) was not specific family-friendly policies but rather the perception that the organization understands and supports family responsibilities. O'Driscoll et al (72) reported very similar findings.]

Such participative approaches may combine both the work situation and the person as targets in a very "personalized" way. Thus, in a study by Arnetz et al (73), each individual workplace of people that had muscu- loskeletal problems was analyzed from an ergonomic point of view, and both physical and psychological stressors were assessed as well. This approach resulted in interventions that were tailored to the individual's work situation, including, for instance, ergonomic improvements, but also coaching for conflict resolution, where necessary. If needed, person-focused consequences were taken as well, such as training. The intervention was very successful in terms of reduced sick days, when the intervention group was compared with a randomized control group, and it resulted in substantial savings. In a similar vein, Vink \& Kompier (74) introduced ergonomic adjustments (plus training) for individual workplaces. This action resulted in clearly improved ergonomic conditions, but also reduced bodily discomfort.

Altogether, such comprehensive approaches that target both the person and the work situation and use a participatory approach, which ensures both empowerment of those involved and a focus on the most pressing problems, are likely to be the most promising ones.

\section{Concluding remarks}

From the considerations that have been presented in this paper, it follows that organizational interventions to reduce stress and improve health have shown their potential to be effective. Moreover, negative effects occur very rarely; therefore, even projects that are not effective are not likely to do harm.

At the same time, the effects found are rather inconsistent. Much more detailed analyses are necessary to determine who is likely to profit from which program under what circumstances. More strong designs are important, but even where they are not possible, a much more careful documentation of what exactly happened at what time could still be helpful. This approach also implies a stronger focus on process variables.

Thus going to the limits of what is possible under given circumstances, both in terms of documentation and data analysis, seems a realistic demand, although still challenging (75), whereas concentrating almost exclusively on the "proper design" is likely to result in defensive exchanges rather than in promising developments.

In the end, we may have to live with the fact that not all targeted effects will be achieved or will be achieved but with side effects such as reduced satisfaction by some. Developing criteria for judging the "overall effectiveness" in terms of a preponderance of positive effects for substantial numbers of people will be one of the challenges for future work along these lines.

Interventions are likely to be the most promising if they involve a participative approach, are based on a 
sound analysis of pressing problems, from which necessary steps are inferred in a systematic way, combine work-directed and person-directed interventions, and ensure management support (56). These criteria imply also that the field of health promotion could profit from a stronger link to the field of organizational development $(55,58)$.

Although my position cautions against too narrow a focus on issues of design, my arguments certainly do imply more careful and stringent efforts at evaluating interventions. A final consideration, therefore, concerns the impact of evaluations.

Many authors argue for a stronger emphasis on economically oriented cost-benefit analyses in order to convince companies and their representatives that healthoriented interventions are worthwhile, because they pay off in the long run $(7,61)$. This step is certainly necessary, but, at the same time, there is no reason to expect dramatic effects from such efforts in terms of convincing management. There are several empirically based arguments for this position. First, there is ample research showing that human decision making, including decision making in organizations, often does not follow sound and rational principles in the economic interest of the organization $(76,77)$. Second, the widespread disinterest $(54,78)$ in sound evaluation studies does not argue for a strictly economic standpoint, which would actually imply a quest for sound evidence. Third, managers who do support health programs often do not only consider financial aspects, but see health and well-being, or "morale", as goals in their own right (54). Fourth, research on the impact of presenting utility information to managers in the context of selection procedures has been sobering. The selection systems that were supported by utility analyses were not more likely, and sometimes were even less likely, to be accepted $(79,80)$. Although results can be improved by the way the information is presented [eg, ease of understanding (81), framing of the information in terms of avoiding loss versus achieving gains (82)], at best one can expect weak effects (81). One aspect that evidently plays an important role in this process is the credibility of the consultants or experts who present the information, for instance, with regard to their vested interest in "selling" the procedure (83).

In line with the importance of the change agent's competence in the field of organizational development (54) and the general tendency of managers to base decisions about projects on how much they trust the judgment of those who present it (77), these results caution against the expectation that sound cost-benefit analyses "will do the job". Rather, the impact of such arguments, and both the acceptance and success of intervention projects, will depend to a considerable degree on trust in those who propose, prepare, and conduct such an intervention. Building trustful professional relationships, therefore, is an extremely important prerequisite for successful interventions that aim at improving people's health.

\section{References}

1. Belkic KL, Landsbergis PA, Schnall PL, Baker D. Is job strain a major source of cardiovascular disease risk? [review]. Scand J Work Environ Health. 2004;30(2):85-128.

2. Nachemson AL, Jonsson E, editors. Neck and back pain: the scientific evidence of causes, diagnosis, and treatment. Philadelphia (PA): Lippincott Williams \& Wilkins; 2000.

3. Matthews KA, Gump BB. Chronic work stress and marital dissolution increase risk of posttrial mortality in men from the Multiple Risk Factor Intervention Trial. Arch Intern Med. 2002;162:309-15.

4. Siegrist J. Effort-reward imbalance at work and health. In: Perrewé PL, Ganster DC, editors. Research in occupational stress and well being, vol. 2. Amsterdam: Elsevier; 2002. p 261-91.

5. Sonnentag S, Frese M. Stress in organizations. In: Borman WC, Ilgen DR, Klimoski RJ, editors. Handbook of psychology, vol 12: industrial and organizational psychology. Hoboken (NJ): Wiley; 2003. p 453-91.

6. Semmer NK. Job stress interventions and organization of work. In: Tetrick LE, Quick JC, editors. Handbook of occupational health psychology. Washington (DC): APA; 2003. p 325-53.

7. Murphy LR, Sauter SL. Work organization interventions: state of knowledge and future directions. Soc Prev Med. 2004;49:79-86.

8. O'Donnell MP, editor. Health promotion in the workplace. 3rd ed. Albany (NY): Delmar; 2002.

9. Kompier M, Cooper C. Introduction: improving work, health and productivity through stress prevention. In: Kompier M, Cooper C, editors. Preventing stress, improving productivity: European case studies in the workplace. London: Routledge; 1999. p 1-8.

10. Van der Klink JJL, Blonk RWB, Schene AH, van Dijk FJH. The benefits of interventions for work-related stress. Am J Public Health. 2001;91:270-6.

11. Bamberg E, Busch C. Betriebliche Gesundheitsförderung durch Stressmanagementtraining: Eine Metaanalyse (quasi)experimenteller Studien [Health promotion at the work site by stress management training: a meta-analysis of (quasi-) experimental studies]. Z Arb Organisationspsychol. 1996;40:127-37.

12. Murphy LR. Stress management in work settings: a critical review of the health effects. Am J Health Promot. 1996;11:112-35.

13. Semmer NK, Zapf D. Gesundheits- und verhaltensbezogene Interventionen in Organisationen [Health- and behavior-related interventions at the worksite]. In: Schuler H, editor. Organisationspsychologie-Gruppe und Organisation [Organizational psychology-groups and organizations]. (Enzyklopädie der Psychologie, Themenbereich D, Serie III, Band 4). Göttingen (Germany): Hogrefe; 2004. p 773-843.

14. Kaluza G. Evaluation von Stressbewältigungstrainings in der primären Prävention-eine Metaanalyse (quasi-) experimenteller Feldstudien. Z Gesundheitspsychol. 1997;5:149-69. 
15. Taris TW, Kompier MAJ, Geurts SAE, Schreurs PJG, Schaufeli WB, de Boer E, et al. Stress management interventions in the Dutch domiciliary care sector: findings from 81 organizations. Int J Stress Manage. 2003;10:297-325.

16. Parker S, Wall T. Job and work design. Thousand Oaks (CA): Sage; 1998.

17. Warr, PB. Well-being and the workplace. In: Kahnemann D, Diener E, Schwarz N, editors. Well-being: the foundations of hedonic psychology. New York (NY): Sage; 1999. p 392412.

18. Kompier M. Job design and well-being. In: Schabracq M, Winnubst J, Cooper C, editors. The handbook of work \& health psychology. 2nd ed. Chichester (UK): Wiley; 2003. p 429-54.

19. Cherns AB. The principles of socio-technical design revisited. Hum Relat. 1987;40:153-62.

20. Herzberg F, Mausner B, Snyderman BB. The motivation to work. 2nd ed. New York (NY): Wiley; 1959.

21. Hackman JR, Oldham GR. Work redesign. Reading (MA): Addison-Wesley; 1980.

22. Wall TD, Clegg CW. A longitudinal field study of group work redesign. J Occup Behav. 1981;2:31-49.

23. Wall TD, Kemp NJ, Jackson PR, Clegg CW. An outcome evaluation of autonomous work groups: a long-term field experiment. Acad Manage J. 1986;29:280-304.

24. Smith MJ, Zehel D. A stress reduction intervention programme for meat processors emphasizing job design and work organization (United States). In: Di Martino V, editor. Preventing stress at work: conditions of work digest, 11 (2). Geneva: International Labour Office; 1991. p 93-113

25. Evans GW, Johansson G, Rydstedt L. Hassles on the job: a study of a job intervention with urban bus drivers. J Occup Behav. 1999;20:199-208.

26. Rydstedt LW, Johansson G, Evans GW. The human side of the road: Improving the working conditions of urban bus drivers. J Occup Health Psychol. 1998;3:161-71.

27. Kompier MAJ, Aust B, van den Berg AM, Siegrist J. Stress prevention in bus drivers: evaluation of 13 national experiments. J Occup Health Psychol. 2000;5:11-31.

28. Spector PE, Jex SM. Development of four self-report measures of job stressors and strain: Interpersonal Conflict at Work Scale, Organizational Constraints Scale, Quantitative Workload Inventory, and Physical Symptoms Inventory. J Occup Health Psychol. 1998;3:356-67.

29. Heaney CA, Price FH, Rafferty J. Increasing coping resources at work: a field experiment to increase social support, improve work team functioning, and enhance employee mental health. J Organ Behav. 1995;16:335-52.

30. Schaubroeck J, Ganster DC, Sime WE, Ditman D. A field experiment testing supervisory role clarification. Pers Psychol. 1993;46:1-25.

31. Semmer NK. Health related interventions in organizations: stages, levels, criteria, and methodology. Soc Prev Med. 2004;49:89-91.

32. Korunka C, Weiss A, Karetta B. Die Bedeutung des Umstellungsprozesses bei der Einführung neuer Technologien: Eine interdisziplinäre Längsschnittstudie. [The impact of the change process when introducing new technology] Z Arb Organisationspsychol. 1993;37:10-8.

33. Antoni CH. Soziale und ökonomische Effekte der Einführung teilautonomer Arbeitsgruppen-eine quasi-experimentelle Längsschnittstudie [Social and economic effects of introducing partially autonomous teams - a quasi-experimental longitudinal study]. Z Arb Organisationspsychol. 1997;41:131-
142.

34. Larsson G, Setterlind S, Starrin B. Routinization of stress control programmes in organizations: a study of Swedish teachers. Health Promot Int. 1990;5:269-78.

35. Meichenbaum D, Fitzpatrick D. A constructivist narrative perspective on stress and coping: stress inoculation applications. In: Goldberger L, Breznitz S, editors. Handbook of stress: theoretical and clinical aspects. 2nd ed. New York (NY): The Free Press; 1993. p 706-23.

36. Bunce D, West MA. Stress management and innovation interventions at work. Hum Relat. 1996;49:209-32.

37. Semmer NK, Zapf D, Greif S. "Shared job strain": a new approach for assessing the validity of job stress measurements. J Occup Organ Psychol. 1996;69:293-310.

38. Cartwright S. Mergers and acquisitions: an update and appraisal. In: Hodgkinson GP, Ford JK, editors. International review of industrial and organizational psychology, vol 20. Chichester (UK): Wiley; 2005. p 1-38.

39. Wanous JP. Organizational entry. 2nd ed. Reading (MA): Addison-Wesley; 1992.

40. Maxwell SC. The persistence of underpowered studies in psychological research: causes, consequences, and remedies. Psychol Methods. 2004;9:147-63.

41. Kompier MAJ, Kristensen TS. Organizational work stress interventions in a theoretical, methodological and practical context. In: Dunham J, editor. Stress in the workplace: past, present and future. London: Whurr Publishers; 2000. p 16490.

42. Frese M, Zapf D. Methodological issues in the study of work stress: objective vs. subjective measurement and the question of longitudinal studies. In: Cooper CL, Payne R, editors. Causes, coping, and consequences of stress at work. Chichester (United Kingdom): Wiley; 1988. p 375-411.

43. Frese M, Semmer NK. Shiftwork, stress and psychosomatic complaints: a comparison between workers in different shift work schedules. Ergonomics. 1986;29:99-114.

44. Semmer NK, McGrath JE, Beehr TA. Conceptual issues in research on stress and health. In: Cooper CL, editor. Handbook of stress and health. 2nd ed. New York (NY): CRC Press; 2005. p 1-43.

45. Gallo LC, Matthews KA. Understanding the association between socioeconomic status and physical health: do negative emotions play a role? Psychol Bull. 2003;129:10-51.

46. Harrison DA, Martocchio JJ. Time for absenteeism: a 20-year review of origins, offshoots, and outcomes. J Manage. 1998;24:305-50.

47. Demerouti E, Bakker AB, Nachreiner F, Schaufeli WB. The job demands-resources model of burnout. J Appl Psychol. 2001;86:499-512.

48. Beehr TA, Glaser KM, Canali KG, Wallwey DA. Back to basics: reexamination of demand-control theory of occupational stress. Work Stress. 2001;15:115-30.

49. Randall R, Griffiths A, Cox T. Evaluating organizational stress-management interventions using adapted study designs. Eur J Work Organ Psychol. 2005;14:23-41.

50. Munz DC, Kohler JM. Do worksite stress management programs attract the employees who need them and are they effective? Int J Stress Manage. 1997;4:1-11.

51. Krohne HW. Individual differences in emotional reactions and coping. In: Davidson RJ, Scherer KR, Goldsmith HH, editors. Handbook of affective sciences. Oxford (United Kingdom): Oxford University Press; 2003. p 698-725.

52. Semmer NK. Control at work: issues of specificity, generality, and legitimacy. In: Perrig WJ, Grob A, editors. Control of 
human behavior, mental processes, and consciousness. Mahwah (NJ): Erlbaum; 2000. p 555-74.

53. Katz D, Kahn RL. The social psychology of organizations. 2nd ed. New York (NY): Wiley; 1978.

54. Terborg JR. Health psychology in the United States: a critique and selective review. Appl Psychol Int Rev. 1998;47:199217.

55. Heaney CA. Worksite health interventions: targets for change and strategies for attaining them. In: Tetrick LE, Quick JC, editors. Handbook of occupational health psychology. Washington (DC): American Psychological Association; 2003. p 304-23.

56. Kompier MAJ, Geurts SAE, Gründemann RWM, Vink P, Smulders PGW. Cases in stress prevention: the success of a participative and stepwise approach. Stress Med. 1998;14:144-68.

57. Schurman SJ, Israel BA. Redesigning work systems to reduce stress: a participatory action research approach to creating change. In: Murhpy LR, Hurrell JJ, Sauter SL, Keita GP, editors. Job stress interventions. Washington (DC): American Psychological Association; 1995. p 235-63.

58. Porras JI, Robertson PJ. Organizational development. In: Dunnette MD, Hough LM, editors. Handbook of industrial and organizational psychology, vol 3. Palo Alto (CA): Consulting Psychologists Press; 1992. p 719-822.

59. Kompier MAJ, Cooper CL, Geurts SAE. A multiple case study approach to work stress prevention in Europe. Eur $\mathbf{J}$ Work Organ Psychol. 2000;9:371-400.

60. Kompier MAJ, Cooper CL, editors. Preventing stress, improving productivity. European case studies in the workplace. London: Routledge; 1999.

61. Beehr TA, O’Driscoll MP. Organizationally targeted interventions aimed at reducing workplace stress. In: Thomas JC, Hersen M, editors. Handbook of mental health in the workplace. Thousand Oaks (CA): Sage; 2002. p 103-19.

62. Semmer NK. Stress, personality, and coping. In: Vollrath ME, editor. Handbook of personality and health. Chichester (United Kingdom): Wiley; 2006. p 73-113.

63. Hobfoll SE. The influence of culture, community, and the nested-self in the stress process: advancing conservation of resources theory. Appl Psychol Int Rev. 2001;50:337-421.

64. Thoits PA. Stressors and problem-solving: the individual as psychological activist. J Health Soc Behav. 1994;35:143-59.

65. Theorell T, Karasek RA. Current relating to psychosocial job strain and cardiovascular disease research. J Occup Health Psychol. 1996;1:9-26.

66. Schaubroeck J, Merritt DE. Divergent effects of job control on coping with work stressors: the key role of self-efficacy. Acad Manage J. 1997;40:738-54.

67. Maes S, Verhoeven C, Kittel F, Scholten H. Effects of a Dutch work-site wellness-health program: The Brabantia Project. Am J Public Health. 1998;88:1037-41.
68. Munz DC, Kohler J, Greenberg CI. Effectiveness of a comprehensive worksite stress management program: combining organizational and individual interventions. Int J Stress Manage. 2001;8:49-62.

69. Aust B, Ducki A. Comprehensive health promotion interventions at the workplace: experiences with health circles in Germany. J Occup Health Psychol. 2004;9:258-70.

70. Reicherts A, Wanous JP, Austin JT. Understanding and managing cynicism about organizational change. Acad Manage Executive. 1997;11:48-59.

71. Saltzstein AS, Ting Y, Saltzstein G. Work-family balance and job satisfaction: the impact of family-friendly policies on attitudes of Federal Government employees. Public Adm Rev. 2001;61:452-67

72. O'Driscoll M, Poelmans S, Spector PE, Kalliath T, Allen TD, Cooper CL et al. Family-responsive interventions, perceived organizational and supervisor support, work-family conflict, and psychological strain. Intern J Stress Manage. 2003;10:326-44.

73. Arnetz BB, Sjögren B, Rydéhn B, Meisel R. Early workplace intervention for employees with musculoskeletal-related absenteeism: a prospective controlled intervention study. J Occup Environ Med. 2003;45:499-506.

74. Vink P, Kompier MAJ. Improving office work: a participatory ergonomic experiment in a naturalistic setting. Ergonomics. 1997;40:435-49.

75. Kristensen TS. Workplace intervention studies. Philadelphia (PA): Hanley \& Belfus, Inc; 2000. Occupational Medicine: State of the Art Reviews, vol 15, p 293-305.

76. Halpern JJ, Stern RN. Debating rationality: nonrational aspects of organizational decision making. Ithaca (NY): Cornell University Press; 1998.

77. Mintzberg H. The manager's job: folklore and fact. Harv Bus Rev. 1975;(July-August):49-61.

78. Cascio WF. Costing human resources. 4th ed. Cincinnati (OH): South Western College Publishing; 2000.

79. Latham GP, Whyte G. The futility of utility analysis. Pers Psychol. 1994;47:31-46

80. Whyte G, Latham G. The futility of utility analysis revisited: when even an expert fails. Pers Psychol. 1997;50:601-10.

81. Carson KP, Becker JS, Henderson JA. Is utility really futile?: a failure to replicate and an extension. J Appl Psychol. 1998;83:84-96.

82. Hazer JT, Highhouse S. Factors influencing managers' reactions to utility analysis: Effects of $S D_{y}$ method, information frame, and focal intervention. J Appl Psychol. 1997;82:10412.

83. Cronshaw SF. LO! The stimulus speaks: the insider's view on Whyte and Latham's "The Futility of Utility Analysis". Pers Psychol. 1997;50:611-15.

Received for publication: 5 May 2006 